\title{
SuperQuads: A Day in the Life; Research Reviews: Color-Number Association, Finger-Length Ratios, Twinning Diets, Athletic Pairs
}

\author{
Nancy L. Segal \\ Department of Psychology, California State University, United States of America
}

\begin{abstract}
The nature and frequency of quadruplet births are reviewed, followed by a close-up look at the 6-year-old monozygotic Mathias quadruplets. This essay is followed by reviews of new twin research on color-number association, male-female twins' finger-length ratios, and links between twinning and dietary practices. The article finishes by focusing on unusual twin athletes in football, basketball and golf, and on twin co-authors of a new book on the 1972 silver medal victory by the United States hockey team.
\end{abstract}

\section{SuperQuads: A Day in the Life}

The dramatically increased rate of multiple births is well known. This is explained by older maternal age at conception and the increased availability of artificial reproductive technologies (ART; Martin et al., 2005). (New research linking dietary practices to increased twinning is summarized below.) It has been estimated that $67 \%$ of twins and $18 \%$ of triplets, quadruplets and quintuplets were conceived naturally in 2000 .

Recent statistics from the Center for Disease Control indicate that triplet, quadruplet and quintuplet births rose $400 \%$ between 1980 and 1998 (Martin et al., 2005). Specifically, the frequency of higher order multiples went from 37.0/1000 live-births to 193.5/1000 live-births during those years. However, the multiple birthrate, while stable since 1999, decreased after 1998. This stabilization may be explained by limits placed on the number of embryos transferred during ART. Limitations were recommended (although not enforced), due to elevated physical risks posed by multiple birth pregnancies for mothers and infants. In 2003, the last year for which data are available, the number of higher

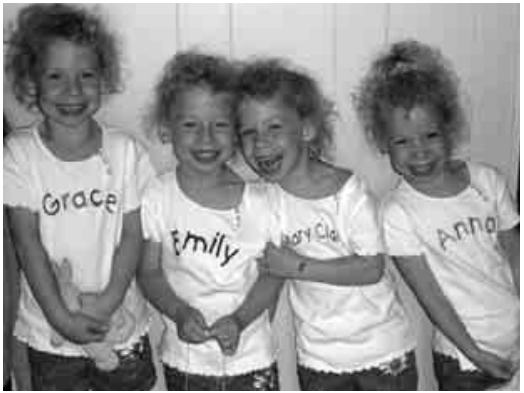

Photo by Nancy Segal, May 30, 2006.

Lexington, South Carolina.

order multiples (live-births) was 7663 , the highest recorded.

The fact that most triplets, quadruplets and quintuplets are polyzygotic and conceived artificially increases interest in sets are that are monozygotic (MZ) and conceived naturally. The 6-year-old Mathias quads of Lexington, South Carolina — Grace, Emily, Mary Claire and Anna - are exemplary. Their mother, Allison, discovered a 'triplet' pregnancy at 9 weeks, but it was not until the 12 th week of her pregnancy that a fourth fetus was identified (Mathias, personal communication, 2002). She was made aware of the physical risks and the availabil- ity of selective termination, but carried the four fetuses to term. The infants were born on February 16, 2000, at 30 weeks' gestation, with birthweights of 2 pounds 10 ounces, 2 pounds 8 ounces, 2 pounds 9 ounces and 2 pounds 6 ounces. They remained in the neonatal intensive care unit for over 2 months, but were generally healthy. Grace and Mary Claire came home at age 2 months, and Emily and Anna came home 2 weeks later. In order to tell them apart, Allison wrote their names on the soles of their feet with a sharpie pen. Today, all four girls are active and healthy.

It is not unusual for MZ co-twins, co-triplets and more to organize themselves into social roles that may or may not be maintained cross-situationally. The identical Dionne quintuplets were described as the 'aggressor' (Annette), the 'matriarch' (Yvonne), the 'independent, happy-go-lucky' (Emilie), the 'baby' (Marie) and the 'unknown quantity’ (Cecile; Blatz, 1938; also see

Address for correspondence: Nancy L. Segal, Department of Psychology, California State University, Fullerton, CA 92834, USA.

E-mail:nsegal@fullerton.edu 
Segal, 2000). The Mathias quads' show similar differentiation into roles as 'leader', 'whiner', 'boss' and 'teaser' (http://www.five.tv/programmes/ extraordinarypeople/quads).

The identical blonde girls are media successes. Their first experience was winning $\$ 10,000$ as 'laughing babies', a segment submitted to America's Funniest Home Video. They continued to win subsequent competitions, earning a trip to Disneyworld in Florida, where they recently captured the grand prize of $\$ 250,000$. They have also been involved in the production of a television commercial for Target stores. Their latest venture, in 2006, involved filming a segment on their early development and first school year with the Discovery Channel (ATIT Productions, in the United Kingdom). In May 2006, I participated in the third installment of this series, which provided a rare opportunity to observe the similarities, differences and social interactions among the members of this unique group.

I had never seen MZ quadruplets in person, only in photos and in film, so before leaving California I had studied the girls' photos on their website (www.mathiasquads.com). Despite having studied hundreds of $M Z$ twin pairs in the past, $M Z$ quads were unusually challenging. The four girls were indistinguishable, except for the names embroidered on their $t$-shirts. Like most parents of twins, their mother, while aware of their zygosity due to DNA testing, highlighted their differences.

\section{Part 1: Interview With Allison Mathias}

The twins' mother was a 27-year-old primagravida when she conceived the quadruplets. She had earned a Bachelor's degree in biology and a Master's degree in public health, with a specialization in maternal-fetal medicine. Given her educational background, she was sensitive to the risks posed by higher order multiple pregnancies. While excited at the prospect of having triplets, the subsequent diagnosis of quadruplets was unsettling. Her husband, Steve, had earned a 2-year degree in computer technology and was working as a systems analyst when I visited the family. He was 34 years of age when the children were born.
Allison believes that the girls' social ordering emerged naturally, apart from differences in parental treatment, but she knows this is difficult to verify. Their levels of maturity and assertiveness follow their birth order, so the possibility that she unknowingly treated them with birth order in mind cannot be dismissed. The girls are also aware of their order of their birth, used as the organizing principle in turn-taking situations. Grace, the first-born and the largest of the four, is the leader. Emily, the secondborn, is the 'vice-president' — she would like to be leader, but lacks Grace's confidence. She is also a whiner. Mary Claire, the third-born, is interesting and very much her own person. She would like to lead.' Anna, the fourth-born, is a baby and 'fulfills that role to a "T"'. She expects to be cared for by her sisters who, in turn, are aware of her needs. Anna teases the others, but they do not tease her back. There have been transient shifts in the social ordering, occurring this past year during the quads' first school year. All four girls experienced separation anxiety from their mother, but at different times first Anna, then Emily, then Mary Claire, and finally Grace. At the end of the school year, Grace witnessed one of her classmates become sick and she wondered where her own mother would be if she were to get sick. This episode caused Grace to temporarily relinquish her leadership role to Emily, upsetting Mary Claire and Anna in the process.

The quads' behavioral differences mean that Allison cannot, and does not, treat them all the same. She punishes Grace differently from the way she punishes Anna - 'Grace is stubborn and hard-headed, while Anna is sensitive'. Allison is also aware of the girls' similarities. They are 'fraidy cats', and easily transmit their fears to one another. At a multiples' picnic held shortly before I arrived, Anna clung to her mother, afraid of a possible thunderstorm. When the other three learned of her concern, they also began to worry. However, when each girl is alone she acts differently from the way she acts with her sisters, illustrative of social-genetic concepts and principles set forth by Scott (1977) and elaborated by Hahn (1990). Specifically, most behavior expressed by highly social species is expressed within social relationships. Genotypic effects may differentially affect individual and joint behaviors, highlighting the importance of the genetic backgrounds of the interactants. The quads 'open up' when they are alone with their mother, and do not act 'silly' like they often do when they are together.

The four girls show similar ability levels in reading and in other cognitive skills. Their mother suggested that their behavioral similarities come from their shared age and gender. When I suggested that their shared genes might also be involved, she was intrigued.

The girls have occupied two bedrooms since they were 3 years old, and sleep two to a room: Grace is paired with Anna, and Emily is paired with Mary Claire, decisions they came to on their own. However, Allison wisely decided the classroom assignments for the quads' first year at school: Grace was paired with Mary Claire, and Emily with Anna. It was reasoned that separating the girls somewhat would deflect unwanted attention from their classmates. Second, by keeping them in two groups of two, everyone had a familiar partner in an unfamiliar setting. It was also explained that had Anna gone with Grace, she would have clung to her sister and allowed her to make decisions. Pairing Anna with Emily (who is less of a leader) was done to encourage Anna's independence. However, class assignments will alter next year: Anna will be with Grace, and Emily will be with Mary Claire. Bedroom arrangements will also be shifted to offer everyone new experiences.

The girls are dressed alike and always have been. What was initially 'too difficult to resist' has become a practical matter. It is easier shopping for one outfit than for four, although finding four copies of the same clothing can be hard.

\section{Part 2: GEMA}

They call themselves GEMA, the merging of their four initials (Grace, Emily, Mary Claire and Anna). The quads were seated around a large dining room table, drawing pictures, when I saw them for the first time. All four used their right hand, although Anna occasionally uses her left.

The staff at ATIT productions wanted me to observe the quads as they completed a series of interactive activities and tasks. The idea was to learn 
more about interquad relations and preferences. I brought along many of the games and puzzles I have used in previous twin research, but this was not research - the quads were surrounded by cameras and lights, and were often asked to repeat a certain action for artistic effect.

The girls first completed a puzzle working in two sets of two. The collaborations were cooperative and congenial, as evidenced by continuous positioning of the puzzle between the two sisters, easy exchange of pieces, attentiveness to the task, positive facial expressions and laughter. This recalled the nature of the social interactions I had observed between 7- to 11-year-old MZ twins who had completed the puzzle in an early study (Segal, 1984). In contrast, the majority of dizygotic (DZ) twins had struggled over placement of the puzzle and possession of the pieces. In the case of the quads, the interactions looked nearly the same across the two pairs, except that Grace subtly directed the activity in her pair.

Questions posed to the girls individually yielded many similar answers. When asked to name a city, three out of four chose New York even though they have never been there. Three of the four chose pink as a favorite color. Two wanted to be ballerinas and one wanted to be an ice skater; only Emily wanted to be a veterinarian. The Mathias family has two dogs and raises chickens in their backyard, giving all the girls considerable experience with animals - why Emily was the only quad to name this as a possible profession is uncertain, but could be an attempt to differentiate. Of course, the preferences of 6-year-olds can change on a given day, so observing the girls over time would identify their interests and talents more accurately. The quads showed some scatter when it came to naming flowers and friends (two chose a daisy and two chose a rose). Best friends differed except for overlap between Anna and Emily, but they all agreed that most of their friends were shared.

The most impressive tendency among the girls was their genuine affection and concern for one another, as well as their ease and comfort when together. In one game, all four were willing to work to earn points that would benefit a sister. Working alone, each was given a sheet of paper with rows of small trees printed on one side and asked to outline as many trees as possible so as to exchange them for points and candy. One minute was allowed for this task. Next, the paper was folded to hide what they had done, and they were told to continue - this time, the points earned would go not to themselves, but to one sister of their choice. (Before beginning, each one repeated the instructions to show that she understood them.) Two outcomes from this activity are noteworthy: first, the number of trees outlined in the first condition (working for self) hardly varied across the children, ranging from 25 to 29 . All of them worked at approximately the same pace, neither too quickly nor too slowly. Second, all the girls worked nearly as hard, or slightly harder, for a sister as for themselves. When I told them this they appeared pleased and happy. This seems striking, given the competitive edge that characterizes most sibling pairs. The somewhat older MZ (and DZ) twins in my early study had worked significantly more for themselves than for their twins, but the self-twin difference was significantly less for $M Z$ twins. I concluded that $M Z$ twins may show greater restraint of selfishness vis-à-vis their co-twin, cooperating more by competing less.

Next, we visited the Cold Stone ice cream shop. I led each girl in separately, allowing her to order while the crew filmed - the aim was to determine if they preferred the same flavors and/or toppings. The first child to enter ordered an orange ice cream cone with gummy bears. Many children love sweet chewy toppings, but orange ice cream is not a common choice. Once she was seated to the side I escorted quad 2 to the counter. She also asked for an orange ice cream cone with gummy bears. Quad 3 changed the pattern somewhat, asking for strawberry ice cream, but with gummy bears. (It turns out that she had ordered orange ice cream 2 days earlier.) Quad 4 wanted chocolate ice cream with M\&Ms. The cones were substantial in size, but it was not long before the girls began asking for dinner - despite their slight builds, they have impressive appetites.

The penultimate activity was obtaining individual samples of dance moves, funny faces and body poses.
Some of the girls were growing tired by then and required some coaxing. Three of the four turned away and shook their bottom from side to side. The only one who did not participate was Anna, who stayed by her mother's side. The final event of the day was the burial of a time capsule in the backyard, a small black case containing items that the quads had chosen. It will be opened when they turn 16 .

\section{Part 3: Closing Remarks}

Several broad themes remained with me following this experience. First, observing $M Z$ quadruplets reveals a great deal about the origins of human behavior. Genes underlie variation in the majority of human traits, but prenatal environments, postnatal environments and/or epigenetic events explain why shared DNA does not guarantee shared behavioral and physical outcomes. Well-known quadruplet and quintuplet sets, such as the Genains and Dionnes, respectively, are wonderful examples of such effects. (The Genains were concordant for schizophrenia, but showed widely varying symptoms and severity, Rosenthal, 1963; the Dionnes were strikingly similar in their physical appearance, but two were color-blind and one had epilepsy, Walls, 1959; Scheinfeld, 1967; also see Brough, 1965.) The Mathias quadruplets are also showing behavioral variation, even as young children. Nevertheless, withinpair differences in behavioral traits are completely compatible with genetic influence on those traits. MZ co-twins, co-triplets and co-quads are not identi$\mathrm{cal}$, but they are more alike than other sibling pairs (Segal, 2005).

Greater successes in managing highrisk pregnancies make it likely that additional $\mathrm{MZ}$ quadruplet sets will be available for study in future years. In the past, quadruplet sets have been mostly examined as case studies, while triplets have often been incorporated into twin studies as three pairs of two. Studying these higher order multiples more systematically will assist parents and teacher in the rearing and educating of these unique children, as well as contribute to a broader understanding of human behavior. 


\section{Research Reviews}

\section{Color-Number Association}

The following case study is rare and intriguing. A British investigator described a pair of 12-year-old MZ male twins, noteworthy for displaying established links between colors and numbers (Hancock, 2006). (The twins' zygosity was assigned based on placental examination, reported by hospital staff.) The associations were apparently traceable to a jigsaw puzzle with which the twins played at age 3 years. An unusual aspect to this study was that knowledge of the origins of the color-number associations was available. Photisms (the production of a color sensation by stimuli to another sensory system, e.g., hearing or taste) did not occur.

The particular issue of interest in this experimental case report was whether naming the color of particular digits would be slower if stimuli were displayed in colors that did not correspond to the twins' established associations. In fact, both twins showed increased reaction time to 'miscolored' stimuli, although a meaningful difference was suggested for only one twin.

The investigator presented some intriguing speculations as to the source of the twins' behaviors. A genetic link was suggested, given that the twins' mother also displayed color-number associations. It was also possible that color, being a key aspect of the twins' environment due to their color-coded clothing, played a role. In addition, both twins were skilled in mathematics. Any or all of these suggestions may explain the observed phenomena. An earlier case study by a different investigator, on twins discordant for synaesthesia (a condition in which a stimulus produces an expected sensation as well as one of a different nature, e.g., color and taste), is also of interest (Smilek et al., 2001).

\section{Finger-Length Ratios}

In recent years there has been considerable attention to the effects of prenatal hormones on behavior. This attention has been prompted by studies of rats, mice and gerbils demonstrating masculinized behavior of females situated close to males in utero (see Segal, 2000, and references therein). Oppositesex human twins pose another naturally occurring situation in which to test related hypotheses. In her landmark study, Koch (1966) did not find that girls from male-female pairs were masculinized so much as boys appeared feminized.

Subsequent to Koch's work, a series of studies using opposite-sex twins have been conducted, but have yielded mixed findings. One problem is that separating intrauterine hormonal effects and social-psychological influences on behavior is challenging. As such, the most persuasive evidence that cross-sex hormones affect some aspects of malefemale twin development comes from work on biological measures. A number of examples are documented by McFadden (2002), who found masculinization of otoacoustic emissions in female twins with twin brothers, and masculinization of auditory evoked potentials in homosexual and bisexual women. It is difficult to tie such characteristics to socialization effects.

Recent work of interest was published by van Anders et al. (2006). These investigators examined the 2D:4D ratio (ratio of the second to fourth finger) in members of same-sex (SS) and opposite-sex (OS) twin pairs. This ratio, which is typically smaller in males, showed masculinizing effects in twin sisters with twin brothers. Specifically, the ratio was significantly lower for OS females, relative to SS females, although the difference was detected in the left hand only. (The authors noted that other studies have variously reported this effect in the right hand, the left hand, or both hands.) In contrast, males from OS and SS pairs did not differ in this measure. This set of findings supports a role for androgenizing effects on females from OS pairs, although replication is warranted. It is impossible to imagine a link between the $2 \mathrm{D}: 4 \mathrm{D}$ ratio and opposite-sex twins' social situation.

\section{$\overline{\text { Twinning Diets }}$}

A recent Scottish study highlighted the effects of dietary factors and genetic background on multiple births following in vitro fertilization (IVF; Haggarty et al., 2006). Intake of folate and vitamin B-12 were assessed in a sample of 602 women receiving fertility treatment. The control group consisted of 932 women who conceived naturally. Nutritional information was extracted from a self-report diet history questionnaire. A statistically significant association was found between folate intake and twin births, with increased folate level linked to a greater probability of multiple birth. However, intake of vitamin B-12 did not show an association with folate in analyses of conception and pregnancy outcome. Women with the AA genotype of MTHFR 1298 were also more likely than women with the CC genotype to conceive or produce a successful birth. As such, increased folate levels among members of the former group might have increased the multiple birth rate following IVF.

Commentary on this paper by Steinman (2006a) included mechanisms that could be associated with the findings reported above. First, it was indicated that low calcium environments elevate the chances of blastomere detachment and monozygotic twinning. Therefore, if a calcium chelator is added to the media used for incubation in IVF, the chances of $\mathrm{MZ}$ twinning could increase. Increased twinning associated with IVF has been documented (see Derom et al., 1987; Edwards et al., 1986; Hecht, 1995). Second, genetic factors may be involved. Genes associated with twinning in cattle and in humans have been identified. In cattle, twin births co-occur with increased concentrations of insulin-like growth factor (IGF), and genes affecting twinning in Norwegian cattle are located close to the IGF gene. Population differences in DZ twinning are also well known, being highest among Black people and lowest among Caucasians. It is also interesting that reduced food supply is associated with reduced twinning rates; Steinman speculates that this may reflect reduced maternal IGF levels.

In a just-released study of 1042 women, Steinman (2006b; Bakalar, 2006) found that eating dairy products increased the chances of women having fraternal twins by a factor of five. This result was based on a comparison of birth outcomes between women who 
ate dairy foods regularly and those who did not eat them at all. Consistent with this view is that IGF levels are low in vegans. It was also noted that recombinant growth hormone is given to cattle in the United States (to increase meat and milk production), but not to cattle in Great Britain. Studies showing a greater increase in twinning in the United States than in Great Britain are cited in Steinman's (2006a) comment. Finally, it was noted that folate has been promoted as a dietary supplement for pregnant women in order to offset neural tube defects, something that may have increased twinning in some countries.

Steinman also referred to the hypothesized link between yam consumption and the high rate of $\mathrm{DZ}$ twinning among the Yoruba of Western Nigeria. As further evidence of this association between diet and twinning, he cited a 1986 study documenting decline in Yoruba twinning rates when people moved from rural to urban areas and altered their diet. More recent work suggests mixed findings. In a case-control study, Ugwonali et al. (1998) found a direct relationship between yam consumption and multiple births among the Yoruba. However, Rasak Tijani, medical director of the Olugbon Hospital, favors a genetic explanation, claiming that residents of other areas follow the same diet and culture, yet do not show the same elevated twinning rate (Ibagere, 2002). A computer search did not turn up current research, and the study linking yams and twinning cited by Steinman (2006b) was published in 1986. More timely research on this question would help resolve this issue.

Research activity also bearing upon the questions raised concerning diet and twinning concern comparative twinning rates on the Finnish mainland and archipelego of Aland and Aboland. Using preindustrial data from 1752 to 1850 , Luumma et al. (1998) found a higher incidence of twinning in the archipelego as compared with the mainland. It was suggested that greater abundance and stability of food sources on the archipelego may be an explanation.

Steinman's (2006b) paper presents provocative work that deserves followup. It would be important to know, for example, if the women consuming dairy products were significantly older than the women who did not, given the association between maternal age and DZ twinning; as such, the zygosity of the twin children would also be of interest. Bakalar's (2006) summary of Steinman's research indicated that children were DZ, but this was not included in his original report. Knowing the ethnic composition of the two groups would also be informative, but because the majority of cases were British the samples may have been somewhat restricted.

Factors influencing twinning are multiple and complex. Increased attention to diet, in combination with genetic factors, promises to highlight important underlying mechanisms. Steinman (2006b) is aware of this. As a cautionary note, he points out that older women and women with family histories of twinning should know that dietary protein from soy is linked to lower levels of IGF (and presumably lower levels of twinning) than protein from casein. However, this group of women might well use this knowledge in the opposite way - to improve their chances of giving birth to a set of twins.

\section{$\overline{\text { Athletic Pairs }}$ \\ National Football League (NFL) Twins}

The 40th pick in the 2006 NFL draft was listed as Daniel Bullocks, a safety from the University of Nebraska (Huppert, 2006, personal communication). He will be playing for the Detroit Lions. However, the 40th pick was also listed as Josh Bullocks, from the University of Nebraska, who will be playing for the New Orleans Saints. Daniel, the older twin by one minute, is 6 feet, one-half inch tall and weighs 212 pounds (http://wtfdetroit.com/forums/ showthread.php? $\mathrm{p}=114105$ \#post 11410 5). His twin brother, Josh, is 6 feet tall and weighs 207 pounds (http://www. nfl.com/draft/profiles/2005/bullocks_ josh). The twins appear to be $\mathrm{MZ}$ as judged by their similar appearance in photographs. They are also the cousins of Evelyn Ashford, the 1984 United States Olympic gold medalist in the 100 meter run (http://en.wikipedia.org/ wiki/Evelyn_Ashford).

I included a chapter on sports in my 2000 book, Entwined Lives. In it, I cited a 1997 New York Times article that referred to eight sets of twins in the NFL (Freeman, 1997). Since, then twins in two other sets have joined: Ronde and Tiki Barber, and Kato and Wasswa Serwanga http://www.twinstuff.com/twinsnfl.htm). The Bullocks brothers raise the total count to eleven twin pairs in the NFL.

\section{Lopez Twins (Basketball)}

Brook and Robin Lopez are 7 feet, 1 inch tall twins who are star basketball players for San Joaquin Valley High School in California (Glionna, 2006). Each twin weighs 250 pounds. Had they been born as singletons rather than as twins, the tall young men would still have attracted attention because they excel across many areas and in unusual ways. Aside from their height, they are honors students with nearly 4.0 GPAs, achievements leading to full scholarships to Stanford University. They were among 24 United States high school students included in McDonald's AllAmerican basketball team. They also listen to classical music and draw cartoon characters.

Given the twins' matched physical and behavioral traits, I was surprised that they were labeled 'fraternal twins' in an article chronicling their achievements. (Clearly, their unusual similarities were responsible for the article being written in the first place.) Included among their differences were hairstyles (one twin wears his hair short, the other wears his hair 'wild'), basketball skills (one twin scores more often and is a natural center, while the other twin tends to block) and social behaviors (one twin is more outgoing, while the other is more reserved). However, these differences appear within the range of differences that MZ co-twins display. More likely than not, the twins are identical and their differences reflect the usual social differentiation that occurs between identical co-twins.

Twin type assignments requires scientific assessment, information that is helpful to twins, as well as to investigators. Next year the Lopez brothers will, hopefully, encounter twin investigators at Stanford who can help settle this question. The right answer will clarify developmental patterns for these twins and for younger pairs of basketball hopefuls.

\section{Hole in Two}

I received an intriguing e-mail message from Dr. Irving I. Gottesman, sent to him from Dr. Len Heston (2006). 
It is reproduced below with slight modifications:

Sixty-six year-old female MZ twins, members of our club here, had a hole-in-one on the same 128-yard hole, at the same time. They were playing in the same threesome. Is there any collector of twin trivia who might be interested in the details of this near spooky incident?

I met Julie Sander and Jane Collins in Palm Springs, California in April 2006, during the annual meeting of the Western Psychological Association. Their golfing achievement had attracted attention from local newspapers and television. The twins explained that a hole in one is unusual, but even more so when it repeats. However, the fact that both twins did this on the same day, and at the same time, may not be so 'spooky' - a growing body of twin studies on sports abilities and interests shows that genetic influence plays a role (Segal, 2000; Stubbe et al., 2005). In fact, these twin's athletic talents extend beyond the golf course — in 1995 , at age 55 , both ran the Boston Marathon. They finished at about the same time — but then they had decided to run together.

\section{Co-Twins/Co-Authors}

Tom and Jerry Caraccioli are co-twins and co-authors of a new book, Striking Silver: The Untold Story of America's Forgotten Hockey Team. Their work was featured in the latest issue of Titan Magazine (McLaughlin, 2006), the alumni publication of California State University, Fullerton, where Jerry received a Bachelor of Arts degree in communications. Until recently, both twins were involved in sports publicity, but for different networks in the same city. They independently met many of the same sports celebrities who asked, 'Haven't I met you already?' Today, Tom has moved to a nearby city where he has established his own business.

\section{$\overline{\text { References }}$}

Bakalar, N. (2006, May 30). Rise in rate of twin births may be tied to dairy case. New York Times.

Blatz, W. E. (1938). The five sisters. New York: William Morrow \& Co.

Brough, J., with the Dionne sisters (1965). We were five. New York: Simon \& Schuster.
Freeman, M. (1997, April 27). Giants' Tiki Barber now must make it on his own. New York Times.

Glionna, J. M. (2006, April 25). 7 feet 1 times 2? A stretch. Los Angeles Times, p. $\mathrm{A} 1,6$.

Derom, C., Vlietinck, R., Derom, R., Van den Berghe, H., \& Thiery, M. (1987). Increased monozygotic twinning rate after ovulation induction. Lancet, 2, 1236-1238.

Edwards, R. G., Mettler, L., \& Walters, D. E. (1986). Identical twins and in vitro fertilization. Journal of In Vitro Fertilization and Embryo Transfer, 3, 114-117.

Haggarty, P., McCallum, H., McBain, H., Andrews, K., Duthie, S., McNeill, G., Templeton, A., Haites, N., Campbell, D., \& Bhattacharya, S. (2006). Effect of $B$ vitamins and genetics on success of invitro fertilisation: Prospective cohort study. Lancet, 6, 1513-1519.

Hahn, M. E. (1990). Approaches to the study of genetic influence on developing social behaviors. In M. E. Hahn, J. K. Hewitt, N. D. Henderson, \& R. H. Benno (Eds.), Developmental behavior genetics: Neural, biometrical and evolutionary approaches (pp. 60-80). New York: Oxford University Press.

Hancock, P. (2006). Monozygotic twins' colour-number association: A case study. Cortex, 42, 147-150.

Hecht, B. R. (1995). The impact of assisted reproductive technology on the incidence of multiple gestation. In L. G. Keith, E. Papiernik, D. M. Keith, \& B. Luke (Eds.), Multiple pregnancy: Epidemiology, gestation and perinatal outcome (pp. 175-190). New York: Parthenon.

Ibagere, E. (2002). Nigeria boasts world's twin capital. Retrieved from BBC News, World Edition, http://news.bbc/co.uk/ 2/hi/Africa/2253845.stm

Koch, H. L. (1966). Twins and twin relations. Chicago: University of Chicago Press.

Luumma, V., Haukioja, E., Lemmeetyinen, R., \& Pikkola, M. (1998). Natural selection on human twinning. Nature, 394, 533-534.

Martin, J. A., Hamilton, B. E., Sutton. P. D., Ventura, S. J., Menacker, F., \& Munso, M.L. (2005). Births: Final data for 2003. National Vital Statistics Reports, 54, 1-115.

Mathias, A. (2002, October 24). Re: Health issues and a question. Retrieved from http://www.tqq.com/tqqdiscweb/_disc1 _copy(1)/0000005e.htm
McFadden, D. (2002). Masculinization effects in the auditory system. Archives of Sexual Behavior, 31, 99-111.

McLaughlin, L. (2006). Double vision. Titan Magazine, p. 29.

Rosenthal, D. (Ed.) (1963). The Genain quadruplets. New York: Basic Books.

Scheinfeld, A. (1967). Twins and supertwins. Baltimore, MD: Penguin Books.

Ugwonali, O. F. C., Okonofua, F. E., Odunsi, K., Jekel, J., Wyshak, G., \& Naftolin, F. (1998, June). White yams (dioscorea rotundata) and socioeconomic status as risk factors for twin births in southwest Nigeria. Ninth International Congress of Twin Studies, Helsinki, Finland.

Scott, J. P. (1977). Social genetics. Behavior Genetics, 7, 327-346.

Segal, N. L. (1984). Cooperation, competition and altruism within twin sets: A reappraisal. Ethology \& Sociobiology, 5, 163-177.

Segal, N. L. (2000). Entwined lives: Twins and what they tell us about human behavior. New York: Plume.

Segal, N. L. (2005). Indivisible by two: Lives of extraordinary twins. Cambridge, MA: Harvard University Press.

Smilek, D., Moffatt, B. A., Pasternak, J., White, B. N., Dixon, M. J., \& Merikle, P. M. (2001). Synaesthesia: A Case study of discordant monozygotic twins. Neurocase, 8, 338-342.

Steinman, G. (2006a). Can the chance of having twins be modified by diet? Lancet, 367, 1461-1462.

Steinman, G. (2006b). Mechanisms of twinning VII. Effects of diet and heredity on the human twinning rate. Journal of Human Reproduction, 51, 405-410.

Stubbe, J. H., Boomsma, D. I., \& De Deus, E. J. C. (2005). Sports participation during adolescence: A shift from environmental to genetic factors. Medicine and Science in Sports and Exercise, 37, 563-570.

van Anders, S. M., Vernon, P. A., \& Wilbur, C. J. (2006). Finger-length ratios show evidence of prenatal hormone-transfer between opposite-sex twins. Hormones and Behavior, 49, 315-319.

Walls, G. L. (1959). Peculiar color blindness in peculiar people. Archives of Opthalmalogy, 62, 41-60.

Wenstrom, K. D., Syrop, C. H., Hammitt, D. G., \& Van Voorhis, B. J. (1993). Increased risk of monochorionic twinning associated with assisted reproduction. Fertility and Sterility, 60, 510-514. 